\title{
Endoscopic and Conservative Management of Chronic Pancreatitis and Its Complications
}

\author{
Alexander Waldthaler Roberto Valente Urban Arnelo J.-Matthias Löhr \\ Department of Upper Abdominal Diseases at Karolinska University Hospital, and Clinical Science, Intervention and \\ Technology (CLINTEC), Karolinska University Hospital, Stockholm, Sweden
}

Keywords

Chronic pancreatitis · Endoscopy · Pancreatic insufficiency · Lithotripsy

\section{Abstract}

Chronic pancreatitis is a progressive inflammatory disease of the pancreas potentially giving rise to several complications. For this reason, patients need long-term care and treatment by medical, interventional, and sometimes surgical measures. This article reviews current state-of-the-art strategies and guidelines for treating chronic pancreatitis with conventional and endoscopic measures.

(c) 2019 S. Karger AG, Basel

\section{Definition, Epidemiology, Causes, and Manifestation}

Chronic pancreatitis (CP) is a chronic inflammatory reaction of the pancreas, often arising as a consequence of long-term exposure to toxic agents, autoimmune or genetically induced inflammatory processes, obstructions to the flow of pancreatic juice, or repeated episodes of acute pancreatitis, eventually leading to changes in the organ's form, structure, and function $[1,2]$. Additionally, secondary complications like pseudocysts, stenoses of the pancreatic or biliary duct or duodenum, and nutritional problems and pain may occur $[1,3-6]$. CP is also a risk factor for pancreatic carcinoma and can have a severe impact on quality of life and life expectancy $[7,8]$.
Although its exact prevalence is almost unknown and has been poorly investigated so far, the incidence of CP is increasing worldwide in a range between 4/100,000 in the UK and the USA and 13.4/100,000 in Finland, correlating with the average alcohol intake [9]. The majority of patients is male and usually aged between 30 and 45 years at disease manifestation [9-11]. In Europe, the most common etiology of $\mathrm{CP}$ is excessive alcohol consumption over a course of several years, in most cases exceeding 80 $\mathrm{g}$ of pure alcohol intake per day over a time of 6-12 years [12]. Cigarette-smoking is a second, independent risk factor that potentiates disease progression in combination with excessive alcohol intake [13]. Genetic causes are less frequent and include mutations in cationic trypsinogen 1 and 2 (PRSS1/2), serine protease inhibitor Kazaltype 1 (SPINK1), cystic fibrosis transmembrane conductance regulator (CFTR), chymotrypsin C (CTRC), carboxypeptidase A1 (CPA1), carboxyl ester lipase (CEL), and calcium-sensing receptor (CASR) [14-16]. In their pangenetic association study, Rosendahl et al. [17] identified a variety of other genetic loci that alter susceptibility to $\mathrm{CP}$, supporting the concept of multiple factors engaging in promoting the disease with a clinically almost stochastically appearing risk. Rare causes include primary hyperparathyroidism as well as posttraumatic states. Pancreas divisum is an independent risk factor for development of CP, but this might have been overestimated in its significance [18]. A biliary etiology of CP has been debated in the past, especially in Anglo-Saxon countries, but newer concepts of the disease accept the model of repeti-

\section{KARGER}

(C) 2019 S. Karger AG, Basel
Alexander Waldthaler, MD

Patientområde Övre buk, C1:77, Karolinska University Hospital Hälsovägen 11

SE-141 86 Stockholm (Sweden)

E-Mail Alexander.Waldthaler@ sll.se 


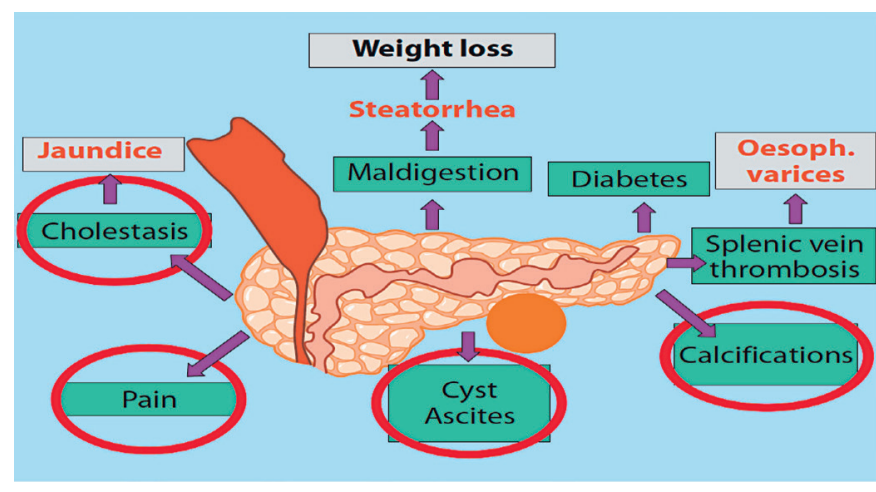

Fig. 1. Complications of chronic pancreatitis (with permission from Löhr et al. [62]).

tive acute episodes of pancreatitis, independently of the underlying stimulus [19].

In summary, $\mathrm{CP}$ is considered a multifactorial disease today; $10-30 \%$ of patients develop a chronic inflammatory mass at the pancreatic head that can lead to secondary problems such as compression of blood vessels, of the bowel, and of the biliary and pancreatic ducts [20]. In patients with portal vein thrombosis, portal hypertension and ascites can arise. Other common secondary changes include the development of pseudocysts and calcifications $[2,21,22]$. Complications of $\mathrm{CP}$ are illustrated in Figure 1.

\section{Basic Approach}

To offer the best clinical care to patients with $\mathrm{CP}$, a comprehensive knowledge of the medical history, symptoms, lifestyle, and imaging and laboratory data is mandatory. Therefore, a complete anamnesis and detailed documentation of a patient's medical history should be obtained. All known risk factors, including alcohol consumption, smoking, and the family history, should be investigated by a systematic approach and a quantitative assessment [23]. Patients who smoke should be advised to stop smoking, patients with alcoholic CP should be advised to stop consuming alcohol, and professional addiction counselling should be offered to increase the chances of long-term abstinence [24]. This process is critical, since it should contain all important information on the positive effects on long-term disease progression and pain, but it should also not damage the relationship between doctor and patient or stop the patient from visiting a doctor because of symptoms of CP even if he does not manage to stop drinking or smoking. For these reasons, longterm care by a single physician specialized in the treatment of $\mathrm{CP}$ patients should be aimed at to increase adherence and compliance.

\section{Diagnosis}

A laboratory work-up should include $\mathrm{Ca}^{++}$(primary hyperparathyroidism), triglycerides, and functional testing of the exocrine and endocrine pancreatic function. In cases with reasonable doubt about the sincerity of a patient concerning alcohol anamnesis, quantification of carbohydrate-deficient transferrin in blood, or ethyl glucuronide in urine or hair, can be useful $[24,25]$. A disease manifestation before 20 years of age, as well as the occurrence of $\mathrm{CP}$ in the setting of recurrent idiopathic pancreatitis, should lead to exclusion of genetic causes, which are reported in up to $63 \%$ in this patient collective [26, 27]. In all patients with so-called idiopathic CP, autoimmune pancreatitis should be ruled out. EUS is considered the most sensitive method for diagnosing early changes in CP [28], and it is an essential tool for differential diagnosis in $\mathrm{CP}$ - that is, for obtaining histologic diagnoses in cases of a possible malignant or autoimmune disease [23].

A meta-analysis comparing image modalities for diagnosing CP revealed a similar accuracy for EUS, MRI, CT, and ERCP and a lower accuracy for transabdominal ultrasound [29]. Since diagnostic ERCP is not the state of the art anymore, EUS, MRI, and CT may be performed, depending on local resources and individual factors such as kidney or thyroid disease, age, comorbidities, and claustrophobia. CT, especially in the sequences without contrast enhancement, has advances over the other modalities for detecting small calcifications. MRI with heavily T2-weighted MR cholangiopancreatography is better in diagnosing the ductal anatomy and can be further optimized in combination with intravenous application of secretin [23].

\section{Nutrition}

Patients with CP have a lower body mass index than healthy individuals, due to several factors. Abdominal pain and a high stool frequency after food intake often lead [30] to smaller meals [31] despite the fact that such patients would need a higher-than-average calorie intake of around $35 \mathrm{kcal} / \mathrm{kg} /$ day [32]. Fat resorption is impaired, most dramatically in patients with pancreatic exocrine insufficiency [33], which can lead to nutritional hypovitaminosis with regard to fat-soluble vitamins $[6,34]$.

In patients with an initial diagnosis of $\mathrm{CP}$, a complete laboratory evaluation including nutritional parameters such as vitamins A, D, B6, and B12 and albumin, electrolyte status, liver function tests, fasting plasma glucose, and $\mathrm{HbA}_{1 \mathrm{c}}$ should be performed. United European Gastroenterology (UEG) recommends screening for malnutrition with nutritional parameters such as prealbumin, retinol-binding protein, vitamin $\mathrm{D}$, and minerals/trace elements [23]. 
In patients with alcohol abuse, deficiencies in vitamins $\mathrm{B} 1, \mathrm{~B} 2$, and $\mathrm{B} 6$ should be ruled out or substituted if necessary, while deficiencies in vitamin B12 and folic acid are rare $[32,35]$. Patients with $\mathrm{CP}$ have a pathological bone metabolism with a 3-fold-higher risk of osteoporosis, which is associated with deficiencies in vitamin $\mathrm{D}$, and in men also in vitamin $\mathrm{K}[34,36-38]$.

\section{Diabetes Mellitus Type 3c}

Diabetes in CP usually refers to pancreoprivic diabetes mellitus (DM). Similar to DM1, it is caused by a dramatic reduction in insulin-producing tissue, and the therapy consists of replacement of the lacking insulin. When treating CP patients with insulin, one should be aware of the higher-than-average risk of hypoglycemia: tissues are highly sensitive to glucose uptake when exposed to insulin. At the same time, synthesis of glucagon by the pancreas is impaired, leading to decreased gluconeogenesis from glycogen in the liver. Ongoing alcohol abuse further increases the risk of hypoglycemia, which is because of the alcohol itself, as well as due to worse therapy compliance and less regular food intake [23]. To rule out a possible overlap with DM2, quantification of C peptide or, in some cases, even the pancreatic polypeptide response may be helpful [23]. Since patients with CP in general are rather young but the 10 -year mortality after primary diagnosis is about $50 \%$, the first aim in diabetes therapy should be avoidance of extreme blood sugar swings. Depending on individual patients' characteristics, a more stringent blood sugar management, similar to type 1 management, may be evaluated [39].

\section{Acid Suppression}

In patients with exocrine pancreatic insufficiency, not only the secretion of pancreatic enzymes, but also secretin-induced secretion of bicarbonate by ductal epithelial cells, as well as the negative feedback mechanism for gastric acid production, are impaired [40, 41]. Furthermore, acid neutralization can be reduced and delayed in the small intestine. As a result, the duodenal $\mathrm{pH}$ may fall below 4 . This leads to a delayed activation of lipase with less activity in the proximal small intestine, causing suboptimal utilization of enzyme activity and resorption capacity [40, 42, 43]. Additionally, bile acid precipitation may affect the enterohepatic cycling of bile [44]. Proton pump inhibitors (PPI) do not have a direct inhibitory effect on pancreatic acinar cells. Therefore, PPI prescription and dose escalation should be evaluated generously in CP patients in case of dyspeptic but also maldigestive symptoms.

\section{Small Bowel Bacterial Overgrowth}

Small bowel bacterial overgrowth (SIBO) is common in CP patients (30-90\%), but this is not related to PPI therapy [45-47]. Therefore, with burping, flatulence, dyspepsia, and other symptoms related to food intake, SIBO should be considered, especially in patients after pancreatic surgery or antibiotic therapy or in those with DM [46].

\section{Pancreatic Enzyme Replacement Therapy}

Pancreatic exocrine insufficiency should be treated with pancreatic enzyme replacement therapy (PERT) with pancreatin in case of clinical or laboratory signs of malabsorption. In most cases, a meal should be accompanied with 40,000-50,000 units of lipase, a snack by half the dose $[23,48]$. Modern pancreatic enzyme preparations consist of capsules filled with so-called microspheres that have an acid-resistant coating. Patients should be instructed to take PERT during their meal. The microspheres mix with the food, pass the pylorus together with the food, and are activated by dissolving their acid-resistant coating in a $\mathrm{pH}$ of 5-6, matching the acidity of a healthy individual's duodenum [49-51]. The effect of PERT on pain has been extensively discussed, but a meta-analysis showed no significant effect [52].

Currently, all pancreatic enzyme preparations are produced from pork-derived ingredients. Therefore, they do not interfere with quantitative stool tests specific for human elastase 1 . It is widely accepted that they can be consumed by patients of Muslim faith (verse 139 of surah al-Baqarah) and Jewish patients (approval from the Chief Rabbi), since no alternatives are available [53].

If PERT is clinically insufficient, several steps may be considered:

- Ensure that the patient knows for which food, when, and how PERT should be taken

- Check if the patient takes PPI; consider PPI dose escalation

- There are considerable variations in the number (100800 per capsule), size (1-3 mm) [50, 51], and consistency $[51,54]$ of preparations; try switching to another product

- PERT is often underdosed [55]; the exact dose recommendation is 2,000 units of lipase per gram of ingested fat [56]; if in doubt, try dose escalation

- Consider if persistent symptoms are compatible with SIBO or other causes of maldigestion rather than exocrine pancreatic insufficiency

The steps are illustrated in Figure 2. 
Fig. 2. Stepwise approach to an insufficient response to pancreatic enzyme replacement therapy (PERT) for chronic pancreatitis patients with pancreatic exocrine insufficiency and maldigestive symptoms. PPI, proton pump inhibitor; SIBO, small bowel bacterial overgrowth.

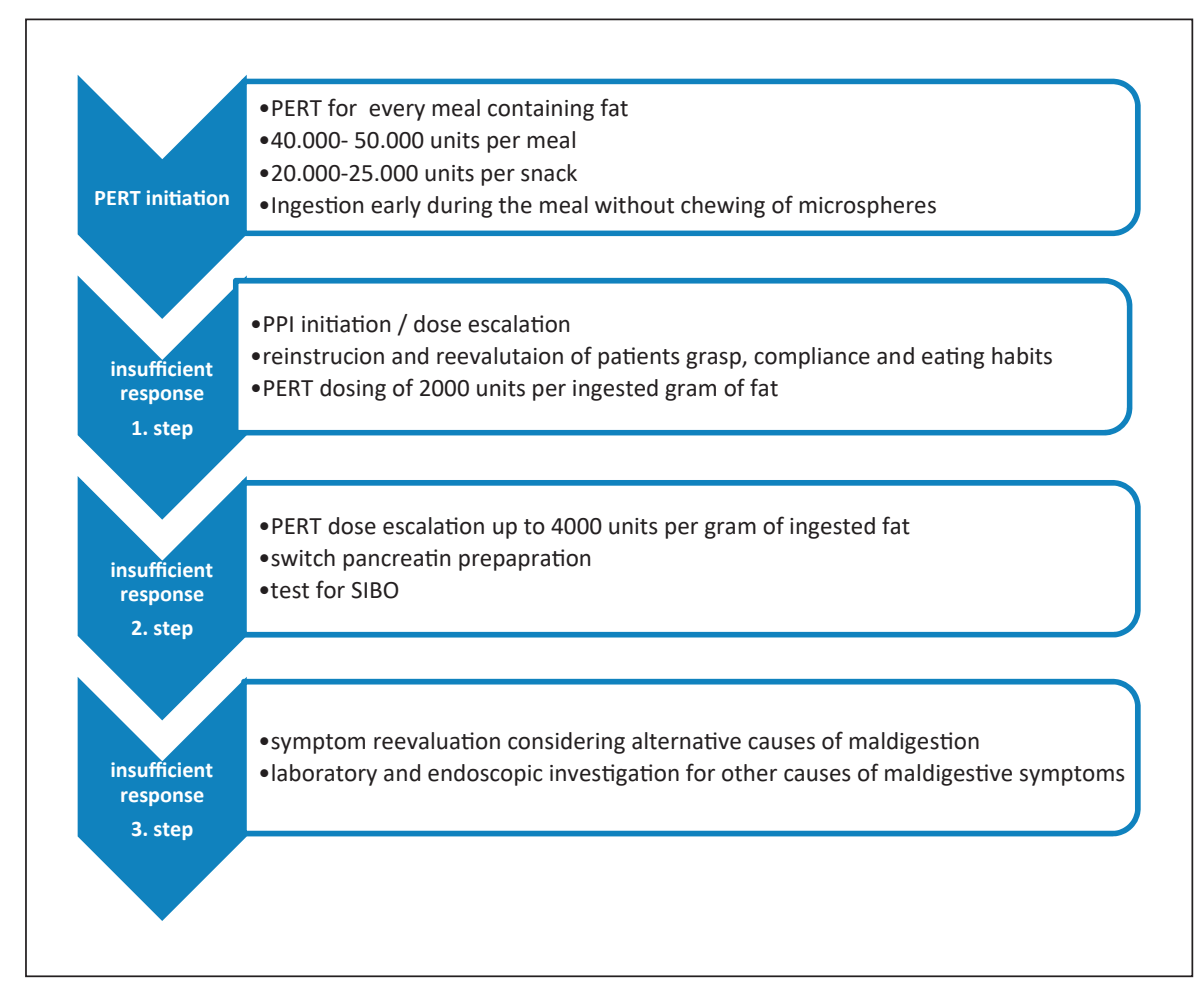

\section{Pain Management}

Pain affects about $80 \%$ of CP patients, constantly or intermittently [4]. The etiology of pain in CP is thought to be multifactorial, with obstructive, hypertensive, ischemic, and inflammatory components. Usually, the pain decreases over the course of the disease [20].

Other causes of abdominal pain, such as peptic disease and synchronous malignancies, should be ruled out, considering that such patients are often exposed to risk factors overlapping between $\mathrm{CP}$, cancer, and peptic disease [57]. Exacerbation of pain can be associated with food intake or an acute bout of pancreatitis and has a significant impact on patients' quality of life and behavior [4, 58]. In general, conservative pain management in $\mathrm{CP}$ follows the WHO stepladder recommendation. Special attention must be given to patients who have issues with alcohol abuse, since they are at higher risk of developing substance addictions [59]. Abstinence from alcohol can have a positive effect on pain [60], and a thorough joint evaluation and intervention by pancreatologists and addiction and pain specialists seems to have the potential for providing a sustainable effect on alcohol use disorders among patients with $\mathrm{CP}$ and alcohol addiction [24]. If opiates are used, preference should be given to preparations with lower potency, in order to avoid not only addictions but also other side effects like loss of appetite and nausea [61]. NSAIDs should not be used due to their gastrointestinal toxicity [23].

\section{Endoscopic Therapy}

Endoscopic therapy (ET) for CP has become a wider research field over the last decades, but it also has been kept under scrutiny. In 2007, a randomized controlled trial was published in The New England Journal of Medicine, stating a clear long-term inferiority of ET to surgery for drainage of the pancreatic duct [63]. This study and its follow-up study [64] were heavily criticized for their weaknesses in methodology. Anyhow, possibly also due to the lack of sufficient data and uniform concepts for ET, the study still had an impact on treatment practice, increasing the importance of surgical therapy in $\mathrm{CP}$. The indication for ET in $\mathrm{CP}$ is long-lasting, since severe pain requires treatment with analgesics [23]. Beneficial effects of ET regarding preservation of pancreatic endocrine and exocrine function have not been demonstrated, and the same applies to surgical drainage procedures [23]. Most of the patients with an indication for ET suffer from pancreatic stones, while about $18 \%$ have ductal strictures only [3]. ET is successful in the majority of patients and may be attempted as the first approach for patients with pain in $\mathrm{CP}$ and a dilated main pancreatic duct (MPD) [23]. Patients who smoke or drink alcohol should be informed on the positive predictive value of discontinuation of alcohol and nicotine consumption for successful ET $[65,66]$. ET is more likely to succeed for ductal obstruction by stones than for strictures [67], as well as for patients with a short disease duration and of a younger age $[23,68]$. 


\section{MPD Strictures}

Pain of the "obstructive type" caused by pancreatic duct obstruction is an established concept in CP that can be treated by decompression [23, 69]. Dilation of the MPD of more than $6 \mathrm{~mm}$ is considered an indicator of increased ductal and parenchymal pressure causative of pain. A ductal stricture in the pancreatic head with ductal dilatation equal to or more than $6 \mathrm{~mm}$ is defined as dominant stricture [23]. Endoscopic dilatation of an MPD stricture alone has no sufficient long-term effect. Instead, the most ample evidence exists for treatment with a single plastic stent [70-75]. Special modifications of plastic stents described for the MPD include a 10-Fr S-shaped plastic stent that has been evaluated with good results in long indwelling times $[71,72,76]$. The majority of patients respond to treatment with single plastic stents, and patients who receive a larger stent have less frequent hospitalizations [77]. There is only one prospective study on multiple plastic stents (MPS) in the pancreatic duct by Costamagna et al. [78], describing the insertion of an increasing number of stents in the pancreatic duct in 19 patients who had previously failed in single-stent therapy and were alternatively considered candidates for surgery. Good treatment success after 6-12 months of ET (94.5\%) and long-term success after a mean follow-up of 38 months $(84 \%)$ were reported. This technique with repeated cannulation and balloon dilatation is technically more challenging than implantation of a single stent and requires more procedures. However, it seems to be able to spare almost all patients who do not respond to singlestent therapy from undergoing surgery. A trial from the same center on the same patient group using fully covered self-expanding metal stents (fcSEMS) in the MPD showed a high frequency of stent migrations as well as de novo strictures arising at the proximal end of the SEMS [79]. Therefore, MPS should be preferred over SEMS treatment in the MPD in CP. UEG mentions pancreatic fcSEMS as an alternative to MPS in patients that fail in single-stent therapy [23].

The consequences of pancreatic plastic stent occlusion are less dramatic than those of the occlusion of biliary stents [75]. Given this background, UEG recommends the treatment of dominant pancreatic duct strictures in CP with a single plastic stent, preferably 8.5 Fr or larger, with preferred stent exchange "on demand" [75] and/or extraction of the stent after 12 months, alternatively after regular stent exchange intervals [23]. The European Society of Gastrointestinal Endoscopy (ESGE) recommends inserting a single 10-Fr plastic stent, with stent exchange planned within 1 year [80]. Criteria for treatment discontinuation are an adequate outflow of contrast medium and passage through the stricture of a 6-Fr catheter [23]. The total duration of ET should not be shorter than 12 months, and MPS can be applied if stricture resolution is not achieved by single-stent treatment. Alternatively, surgery should be discussed [23, 80].

At our center, we follow these recommendations for the most part, but prefer 3 months of elective controls and exchanges of plastic stents in the MPD over long indwelling durations or "on-demand" strategies, with the aim of avoiding symptomatic stent dysfunctions and allowing an earlier switch from single stents to MPS in case of an insufficient response to ET.

\section{Pancreatic Stones}

Stone treatment in the MPD is an effective treatment: the best predicting factor for successful ET of symptomatic $\mathrm{CP}$ in a randomized controlled trial was the presence of ductal stones in the pancreatic head [67]. UEG discourages basket stone extraction attempts with stones larger than $5 \mathrm{~mm}$ without prior extracorporeal shock wave lithotripsy (ESWL) because of the higher risk of therapy failure and complications [23]. In expert centers, ESWL is successful in fragmenting most larger radiopaque stones and therefore can be considered as first-step treatment for radiopaque stones greater than $4 \mathrm{~mm}$ in size obstructing the MPD before endoscopic extraction of stone fragments [81]. ESWL alone can be as effective as ESWL with endoscopic stone fragment extraction [67], but it can lead to complications. A newer approach is the use of peroral pancreatoscopy (POP) with lithotripsy for stone clearance. Howell et al. [82] first described MPD stone removal under direct visualization using an electrohydraulic lithotripsy (EHL) probe in 1999. A systematic review from 2017 including 88 patients from 10 publications, among them 2 prospective studies, showed high treatment success rates with acceptable complication rates [83]: 5 studies used EHL, 4 studies used laser, 1 study used a basket for stone extraction, 1 study compared laser with EHL, and 1 study used a combination of ESWL first, followed by EHL during POP. The study in which ESWL had been performed before POP described an exceptionally low treatment success $(43 \%)$ and the highest complication rate $(28 \%)$ [84]. In a recent retrospective study using EHL in 21 patients, a high rate of stone clearance $(88.2 \%)$ after a mean of 1.29 sessions and a low rate of complications (1 mild case of pancreatitis) were reported [85]. Figure 2 shows treatment with direct visualization of the stone and EHL via POP in CP. Laser lithotripsy may be more powerful than EHL, while EHL treatment is less expensive, but there are very limited data. Overall, there is no clear evidence of one method being superior to the other.

\section{Biliary Stenosis}

Jaundice in CP arises due to compression of the intrapancreatic portion of the common bile duct by an inflammatory mass in the pancreatic head $[2,21,22]$. In this 
case, drainage of the obstructed biliary tract is indicated to avoid secondary problems like cholangitis, liver damage, or secondary biliary cirrhosis [86]. Interventional endoscopic treatment with implantation of plastic stents for patients with CP is almost always technically successful and achieves good short-term clinical outcomes [22, 87, 88]. Nevertheless, biliary strictures caused by CP have the worst chance of long-term success after ET of all benign causes $[89,90]$. If an acute inflammatory episode is ongoing at the time of stricture development, chances are better. On the other hand, in the presence of calcifications of the pancreatic head as a sign of a long-lasting inflammatory situation, chances for long-term stricture resolution by ET are worse [91, 92]. Therefore, endoscopic treatment of CP patients with benign biliary strictures (BBS) consists of repeated ERCP interventions that can lead to a considerable cumulative risk of procedure-related complications as well as patient stress, radiation exposure, and costs [91] with uncertain long-term success.

Treatment of BBS with a single plastic stent has been abandoned because of poor long-term results [93]. Biliary MPS implantation in patients with calcifying CP showed persistent stricture resolution in $60 \%$ of patients after a medium therapy duration of 21.1 months with 3 -month stent exchange intervals [94]. This would imply an average number of $8 \mathrm{ERCP}$ per patient. Since chances for further long-term improvement after an ET duration of more than 12 months are slim, a threshold of 12 months of ET duration is widely accepted [91]. Still, this requires 4-5 procedures with stent exchange intervals of 3-4 months. If plastic stent exchanges are not performed regularly, there is a high risk of secondary complications, such as stent occlusion and cholangitis [95].

SEMS are an alternative to plastic stents. The use of uncovered SEMS in CP patients with biliary stricture was first described in 1994 by Deviere et al. [96]. Today, uncovered or partially covered SEMS should not be used in BBS because of the risk of stent ingrowth and secondary strictures caused by irritation by the uncovered portion, even if long patency rates and few problems with dislocations have been described [23, 96-98]. fcSEMS appear to be as effective as MPS, but they require fewer ERCP to achieve clinical success $[89,99]$. A randomized controlled trial on 60 patients with CP using MPS versus fcSEMS over a period of 6 months resulted in 92 and $90 \%$ stricture resolution, respectively, 2 years after stent removal, with similar complication rates [100]. A second randomized study comparing MPS versus SEMS in BBS mostly included post-liver transplant strictures, and only about one-third of the patients had CP [89]. In that study, the SEMS were removed after 6 months, but exchanged for new SEMS if necessary. All strictures had resolved after 12 months. A systematic review concluded that covered SEMS provided better results than MPS in BBS caused by
CP. It is noteworthy that 3 studies were included in the review that actually only used single-stent implantation [101], which may have had an impact on the conclusion.

Common concerns when implanting fcSEMS are stent dislocations and cholecystitis. To prevent stent dislocations, anchoring devices and flares have been developed, with a positive effect on migration events [102]. On the other hand, in a small portion of patients, de novo biliary strictures from irritations caused by anchoring devices have been described [103, 104].

Studies comparing the risk of cholecystitis when using covered versus uncovered SEMS have been carried out solely on patients with malignant biliary obstructions. Meta-analyses yielded heterogeneous results for these patients [105-107]. Tumor properties, such as invasion of the feeding artery of the gallbladder and the orifice of the cystic duct, rather than stent choice have been identified as influencing the cholecystitis rate [108, 109]. In conclusion, even if there is a small risk of cholecystitis, it is so small that it should not adversely influence the endoscopist's stent choice.

Critical questions when discussing pros and cons of SEMS over MPS are the ideal indwelling time and the total therapy duration with fcSEMS. A meta-analysis including 37 studies and 1,677 patients found a median stenting duration of 4.4 months [110], while another meta-analysis of 22 studies with 1,298 patients found a lower stricture recurrence with 6 months than with 3 months or less of stent therapy [99]. A prospective multicenter study used fcSEMS with a stent indwelling duration of 10-12 months in 177 patients with BBS; among those 127 with $\mathrm{CP}$, it showed that all attempted fcSEMS removals were successful after a mean period of 11.3 months, even though fcSEMS could not be removed in the first attempt from 6 patients [111]. Stent migration increased from $5 \%$ at 6 months to $18.3 \%$ at 12 months, and stricture resolution was observed in $90.5 \%$ of the CP cases. The maximum recommended indwelling time for the fcSEMS type used in that study is 12 months, while other manufacturers mostly set a limit of 6 months.

Probably also due to this, the ESGE and UEG recommend 6 months of fcSEMS therapy. In theory, an indwelling time of 12 months could be attempted to increase the effectivity of ET in BBS without additional stent exchanges. This could be done either by using the fcSEMS according to the manufacturer, which allows a 12-month indwelling time, or by off-label use of other fcSEMS on the market, possibly with antimigration properties to reduce the fairlyhigh incidence of dislocations during a 12-month indwelling time.

In selected $\mathrm{CP}$ patients not achieving stricture resolution and not suitable for surgery, 12-month exchange intervals make long-term ET more efficient, but further studies are required to prove this concept. With such long 

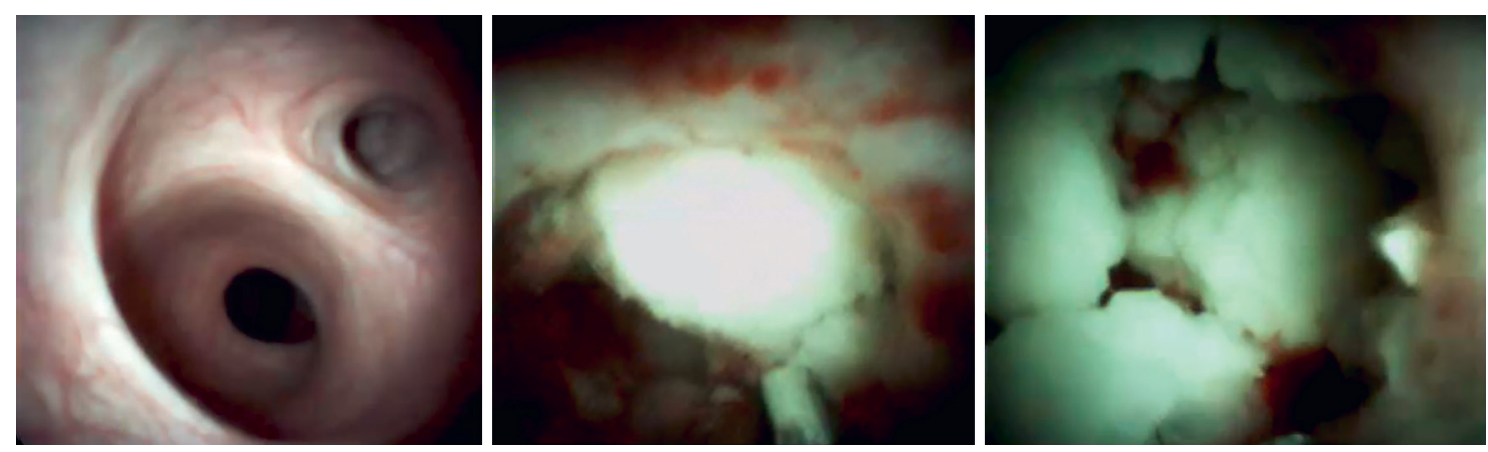

Fig. 3. Direct visualization of wide pancreatic side branches and fragmentation of a pancreatic stone by electrohydraulic lithotripsy via peroral pancreatoscopy.

intervals between ERCP, a save recall system should be established to avoid complications from missed followup ERCP.

In summary, if correctly applied, MPS as well as fcSEMS regimes can be efficient in the majority of patients with BBS associated with CP. Surgery should be applied in nonresolving cases. In the future, stretching the fcSEMS indwelling times to 12 months may dramatically reduce the need for ERCP procedures compared to the 3-month exchange intervals with plastic stents (Fig. 3).

\section{Pancreatic Pseudocysts}

Pancreatic pseudocysts (PPC) are common in CP (20$40 \%$ ) and often arise as a consequence of an acute bout of pancreatitis. Spontaneous resolution can be expected within the first 6 weeks, but rarely later than after 12 weeks [112]. In a multivariate analysis, a pseudocyst size smaller than $4 \mathrm{~cm}$ in diameter was the only favorable factor for spontaneous resolution [113]. Indications for PPC treatment include the presence of symptoms, complications (infection, bleeding, or rupture), or compression of surrounding structures with present or immanent secondary problems such as cholestasis, thrombosis, and duodenal obstruction. The interventional risk from drainage of pancreatic fluid collections is low, and they are suited best for EUS drainage if a fibrous wall more than $5 \mathrm{~mm}$ thick is present. EUS is superior to surgical drainage regarding costs, patient stress, and mortality, while long-term morbidity and success rates are comparable $[114,115]$.

Asymptomatic and uncomplicated PPC should not be drained, especially if small $(<4 \mathrm{~cm})$. The incidence of complications rises if a PPC is larger than $5 \mathrm{~cm}$ in size [116]. Therefore, UEG states that cysts that do not resolve and are larger than $5 \mathrm{~cm}$ may be drained even if asymptomatic [23]. Transpapillary drainage is preferred over transmural drainage if there is communication with the MPD and it is technically possible, since lower complication rates and similar long-term success rates have been observed [80].
It is not easy to predict whether a PPC can be reached transpapillarily, and cases in which an ERP should be attempted are not clearly defined. According to 1 study, PPC are connected to the pancreatic ductal system in 22$57 \%$ of cases [117]. ERP can also be useful to detect and treat a possible pancreatic duct rupture after an acute bout of pancreatitis, which decreases the chances of successful long-term treatment with EUS drainage. In most cases, MR cholangiopancreatography and/or EUS can provide clues about the ductal anatomy and help deciding whether or not to expose a patient to the interventional risk of an ERP [118]. If transpapillary drainage is not possible, EUS-guided drainage of PPC should be attempted [119]. This should be done under antibiotic prophylaxis to avoid secondary infection and abscess formation in PPC [120]. After access has been established, insertion of several double-pigtail stents should be performed [23]. A modern alternative to insertion of MPS approved by UEG is the use of lumen-apposing metal stents (LAMS).

Modern LAMS can be inserted in a single step without additional devices, minimizing the risk of loss of position during insertion. UEG suggests they may be favorable if a cyst's contents are suspected to be thicker than the thin pancreatic juice of a classic PPC, like in walled-off necrosis [23]. LAMS offer a greater lumen that in the further course may be passed with a gastroscope to mobilize the cyst's contents if necessary [121]. In contrast, a study on pancreatic necrosectomy using LAMS and a meta-analysis on PPC drainage with SEMS found higher costs but no clear advantage over plastic stent use [122, 123], while a recently published multicenter study found superiority of LAMS over plastic stenting concerning clinical success, complication rates, and procedure duration in PPC treatment [124]. The recommended maximal indwelling time for modern one-step insertion LAMS is 60 days, while UEG recommends that stents for PPC drainage be left for a minimum of 2 months. General practice at our center is LAMS extraction after about 2 months, although longer indwelling times did not lead to complications in our ex- 
perience as well as according to multiple personal communications. Pigtail stents can be left in place for longer periods or until spontaneous dislocation.

\section{Celiac Plexus Block}

EUS-guided celiac plexus block is safer than previously used blind approaches. Neurodestructive methods with alcohol or phenol are not recommended, since they carry a high risk of serious complications such as severe deafferentation syndromes, while serious complications are rare if local anesthetics are used [125]. Local anesthetics, however, are only effective in half of the patients with a long-term pain relief for more than 24 weeks in only $10 \%$ of patients [126]. Acute adverse effects of celiac plexus block are reported for about $40 \%$ of patients, and they include transient worsening of pain, diarrhea, and hypotension [127]. For these reasons, celiac plexus block should be restricted to selected, severe cases of CP-related pain that are untreatable with other approaches [23].

\section{EUS-Guided Ductal Drainage}

Cannulation of the papilla of Vater is successful in a vast majority of ERCP attempts [128], but in some cases an alternative access has to be established. Several case reports have described EUS drainage of the MPD in benign conditions [129] and unresectable pancreatic cancer [130] as a salvage access route in patients with strong indication for ductal drainage because of recurrent pancreatitis. Access can be transduodenal or transgastric [131] depending on the position of the ductal obstruction. In the largest meta-analysis of EUS-guided biliary drainage (EUS-BD) so far, higher complication rates compared to ERCP have been described [132]. However, an individually higher risk of complications from any procedure may be indicated by failed primary biliary cannulation in cases selected for EUS-BD. A retrospective study found a higher complication rate for endoscopic precut papillotomy than for the EUS-guided rendezvous procedure after failed primary biliary cannulation [133]. Complication rates in EUS-guided drainage procedures have been shown to decrease with growing experience of centers and single endoscopists $[134,135]$. Only recently, 3 prospective randomized trials comparing ERCP and EUS-BD in patients with malignant biliary obstruction showed largely equivalent or better results in the EUS-BD group [136-138]. Interestingly, when transduodenal EUS-BD was performed, no complications arose from stent dislocation after a stable enterobiliary fistula had formed [137]. In theory, this may also be applied to patients with $\mathrm{CP}$ and BBS not responding to transpapillary stent therapy and not suitable for operation. Bypassing the inflammatory mass of the pancreatic head with a fistula may be a long-term concept for these patients, without foreign bodies facilitating bacterial colonization and obstruction. However, further evaluation is needed to validate this concept.

\section{Disclosure Statement}

J.-M. Löhr has received honoraria from Mylan, Abbott, and Nordmark. U. Arnelo has received honoraria from Boston Scientific.

\section{References}

1 Klöppel G, Maillet B. Chronic pancreatitis: evolution of the disease. Hepatogastroenterology. 1991 Oct;38(5):408-12.

2 Klöppel G, Detlefsen S, Feyerabend B. Fibrosis of the pancreas: the initial tissue damage and the resulting pattern. Virchows Arch. 2004 Jul;445(1):1-8.

3 Rösch T, Daniel S, Scholz M, Huibregtse K, Smits M, Schneider T, et al.; European Society of Gastrointestinal Endoscopy Research Group. Endoscopic treatment of chronic pancreatitis: a multicenter study of 1000 patients with long-term follow-up. Endoscopy. 2002 Oct;34(10):765-71.

4 Anderson MA, Akshintala V, Albers KM, Amann ST, Belfer I, Brand R, et al. Mechanism, assessment and management of pain in chronic pancreatitis: recommendations of a multidisciplinary study group. Pancreatology. 2016 Jan-Feb;16(1):83-94.

5 Pan J, Xin L, Wang D, Liao Z, Lin JH, Li BR, et al. Risk Factors for Diabetes Mellitus in Chronic Pancreatitis: A Cohort of 2,011 Patients. Medicine (Baltimore). 2016 Apr; 95(14):e3251.
6 Martínez-Moneo E, Stigliano S, Hedström A, Kaczka A, Malvik M, Waldthaler A, et al. Deficiency of fat-soluble vitamins in chronic pancreatitis: a systematic review and metaanalysis. Pancreatology. 2016 Nov-Dec;16(6): 988-94.

7 Wassef W, DeWitt J, McGreevy K, Wilcox M, Whitcomb D, Yadav D, et al. Pancreatitis Quality of Life Instrument: A Psychometric Evaluation. Am J Gastroenterol. 2016 Aug; 111(8):1177-86.

8 Raimondi S, Lowenfels AB, Morselli-Labate AM, Maisonneuve P, Pezzilli R. Pancreatic cancer in chronic pancreatitis; aetiology, incidence, and early detection. Best Pract Res Clin Gastroenterol. 2010 Jun;24(3):349-58.

9 Lévy P, Domínguez-Muñoz E, Imrie C, Löhr M, Maisonneuve P. Epidemiology of chronic pancreatitis: burden of the disease and consequences. United European Gastroenterol J. 2014 Oct;2(5):345-54.

10 Dufour MC, Adamson MD. The epidemiology of alcohol-induced pancreatitis. Pancreas. 2003 Nov;27(4):286-90.
11 Lankisch PG, Assmus C, Maisonneuve P, Lowenfels AB. Epidemiology of pancreatic diseases in Lüneburg County. A study in a defined German population. Pancreatology. 2002;2(5):469-77.

12 Lankisch PG, Seidensticker F, Löhr-Happe A, Otto J, Creutzfeldt W. The course of pain is the same in alcohol- and nonalcohol-induced chronic pancreatitis. Pancreas. 1995 May; 10(4):338-41.

13 Law R, Parsi M, Lopez R, Zuccaro G, Stevens T. Cigarette smoking is independently associated with chronic pancreatitis. Pancreatology. 2010;10(1):54-9.

14 Whitcomb DC. Genetic aspects of pancreatitis. Annu Rev Med. 2010;61(1):413-24.

15 Fjeld K, Weiss FU, Lasher D, Rosendahl J, Chen JM, Johansson BB, et al. A recombined allele of the lipase gene CEL and its pseudogene CELP confers susceptibility to chronic pancreatitis. Nat Genet. 2015 May;47(5):518-22.

16 Witt H, Beer S, Rosendahl J, Chen JM, Chandak GR, Masamune A, et al. Variants in CPA1 are strongly associated with early onset chronic pancreatitis. Nat Genet. 2013 Oct; 45(10):1216-20. 
17 Rosendahl J, Kirsten H, Hegyi E, Kovacs P, Weiss FU, Laumen $\mathrm{H}$, et al.; all members of the PanEuropean Working group on ACP. Genome-wide association study identifies inversion in the CTRB1-CTRB2 locus to modify risk for alcoholic and non-alcoholic chronic pancreatitis. Gut. 2018 Oct;67(10):185563.

18 Lin TK, Abu-El-Haija M, Nathan JD, Palermo JP, Barth B, Bellin M, et al. Pancreas divisum in pediatric acute recurrent and chronic pancreatitis: report from INSPPIRE. J Clin Gastroenterol. 2018. [Epub ahead of print]

19 Whitcomb DC, Frulloni L, Garg P, Greer JB, Schneider A, Yadav D, et al. Chronic pancreatitis: an international draft consensus proposal for a new mechanistic definition. Pancreatology. 2016 Mar-Apr;16(2):218-24.

20 Layer P, DiMagno EP. Early and late onset in idiopathic and alcoholic chronic pancreatitis. Different clinical courses. Surg Clin North Am. 1999 Aug;79(4):847-60.

21 Scott J, Summerfield JA, Elias E, Dick R, Sherlock S. Chronic pancreatitis: a cause of cholestasis. Gut. 1977 Mar;18(3):196-201.

22 Eickhoff A, Jakobs R, Leonhardt A, Eickhoff JC, Riemann JF. Endoscopic stenting for common bile duct stenoses in chronic pancreatitis: results and impact on long-term outcome. Eur J Gastroenterol Hepatol. 2001 Oct; 13(10):1161-7

23 Löhr JM, Dominguez-Munoz E, Rosendahl J, Besselink M, Mayerle J, Lerch MM, et al.; HaPanEU/UEG Working Group. United European Gastroenterology evidence-based guidelines for the diagnosis and therapy of chronic pancreatitis (HaPanEU). United European Gastroenterol J. 2017 Mar;5(2):15399.

24 Lang MB, Segersvärd R, Grundsten M, Segerdahl M, Arnelo U, Permert J, et al. Management of alcohol use disorders in patients with chronic pancreatitis. JOP. 2012 Nov; 13(6):654-9.

25 Fucci N, Gili A, Aroni K, Bacci M, Carletti P, Pascali VL, et al. Monitoring people at risk of drinking by a rapid urinary ethyl glucuronide test. Interdiscip Toxicol. 2017 Dec;10(4):15562

26 Löhr JM. What are the useful biological and functional markers of early-stage chronic pancreatitis? J Gastroenterol. 2007 Jan;42 Suppl 17:66-71.

27 Jalaly NY, Moran RA, Fargahi F, Khashab MA, Kamal A, Lennon AM, et al. An Evaluation of Factors Associated With Pathogenic PRSS1, SPINK1, CTFR, and/or CTRC Genetic Variants in Patients With Idiopathic Pancreatitis. Am J Gastroenterol. 2017 Aug; 112(8):1320-9.

28 Kahl S, Glasbrenner B, Leodolter A, Pross M, Schulz HU, Malfertheiner P. EUS in the diagnosis of early chronic pancreatitis: a prospective follow-up study. Gastrointest Endosc. 2002 Apr;55(4):507-11.

29 Issa Y, Kempeneers MA, van Santvoort HC, Bollen TL, Bipat S, Boermeester MA. Diagnostic performance of imaging modalities in chronic pancreatitis: a systematic review and meta-analysis. Eur Radiol. 2017 Sep;27(9) 3820-44.

30 Layer P, von der Ohe MR, Holst JJ, Jansen JB, Grandt D, Holtmann G, et al. Altered post- prandial motility in chronic pancreatitis: role of malabsorption. Gastroenterology. 1997 May;112(5):1624-34.

31 Bhardwaj P, Thareja S, Prakash S, Saraya A. Micronutrient antioxidant intake in patients with chronic pancreatitis. Trop Gastroenterol. 2004 Apr-Jun;25(2):69-72.

32 Duggan S, O’Sullivan M, Feehan S, Ridgway $P$, Conlon K. Nutrition treatment of deficiency and malnutrition in chronic pancreatitis: a review. Nutr Clin Pract. 2010 Aug;25(4):36270.

33 Joffe BI, Krut L, Mendelson D, Seftel HC. Oral fat tolerance studies in chronic pancreatitis. Am J Gastroenterol. 1973 Jun;59(6):522-7.

34 Stigliano S, Waldthaler A, Martinez-Moneo E, Lionetto L, Robinson S, Malvik M, et al. Vitamins $\mathrm{D}$ and $\mathrm{K}$ as Factors Associated with Osteopathy in Chronic Pancreatitis: A Prospective Multicentre Study (P-BONE Study). Clin Transl Gastroenterol. 2018 Oct;9(10): 197.

35 Glasbrenner B, Malfertheiner P, Büchler M, Kuhn K, Ditschuneit H. Vitamin B12 and folic acid deficiency in chronic pancreatitis: a relevant disorder? Klin Wochenschr. 1991 Feb;69(4):168-72.

36 Haas S, Krins S, Knauerhase A, Löhr M. Altered bone metabolism and bone density in patients with chronic pancreatitis and pancreatic exocrine insufficiency. JOP. 2015 Jan; 16(1):58-62.

37 Haaber AB, Rosenfalck AM, Hansen B, Hilsted J, Larsen S. Bone mineral metabolism, bone mineral density, and body composition in patients with chronic pancreatitis and pancreatic exocrine insufficiency. Int J Pancreatol. $2000 \mathrm{Feb} ; 27(1): 21-7$

38 Duggan SN, O’Sullivan M, Hamilton S, Feehan SM, Ridgway PF, Conlon KC. Patients with chronic pancreatitis are at increased risk for osteoporosis. Pancreas. 2012 Oct;41(7): 1119-24.

39 Seicean A, Tantău M, Grigorescu M, Mocan T, Seicean R, Pop T. Mortality risk factors in chronic pancreatitis. J Gastrointestin Liver Dis. 2006 Mar;15(1):21-6.

40 Bovo P, Cataudella G, Di Francesco V, Vaona B, Filippini M, Marcori M, et al. Intraluminal gastric $\mathrm{pH}$ in chronic pancreatitis. Gut. 1995 Feb;36(2):294-8.

41 Saunders JH, Cargill JM, Wormsley KG. Gastric secretion of acid in patients with pancreatic disease. Digestion. 1978 Jul-Aug;17(4): 365-9.

42 Dutta SK, Russell RM, Iber FL. Impaired acid neutralization in the duodenum in pancreatic insufficiency. Dig Dis Sci. 1979 Oct;24(10): 775-80.

43 Geus WP, Eddes EH, Gielkens HA, Gan KH, Lamers CB, Masclee AA. Post-prandial intragastric and duodenal acidity are increased in patients with chronic pancreatitis. Aliment Pharmacol Ther. 1999 Jul;13(7): 937-43.

44 Dutta SK, Anand K, Gadacz TR. Bile salt malabsorption in pancreatic insufficiency secondary to alcoholic pancreatitis. Gastroenterology. 1986 Nov;91(5):1243-9.

45 Ratuapli SK, Ellington TG, O’Neill MT, Umar SB, Harris LA, Foxx-Orenstein AE, et al. Proton pump inhibitor therapy use does not predispose to small intestinal bacterial over- growth. Am J Gastroenterol. 2012 May; 107(5):730-5.

46 Capurso G, Signoretti M, Archibugi L, Stigliano S, Delle Fave G. Systematic review and meta-analysis: small intestinal bacterial overgrowth in chronic pancreatitis. United European Gastroenterol J. 2016 Oct;4(5):697-705.

47 Choung RS, Ruff KC, Malhotra A, Herrick L, Locke GR 3rd, Harmsen WS, et al. Clinical predictors of small intestinal bacterial overgrowth by duodenal aspirate culture. Aliment Pharmacol Ther. 2011 May;33(9):1059-67.

48 Layer P, Keller J. Lipase supplementation therapy: standards, alternatives, and perspectives. Pancreas. 2003 Jan;26(1):1-7.

49 Gan KH, Geus WP, Bakker W, Lamers CB, Heijerman HG. In vitro dissolution profiles of enteric-coated microsphere/microtablet pancreatin preparations at different $\mathrm{pH}$ values. Aliment Pharmacol Ther. 1996 Oct;10(5): 771-5.

50 Halm U, Löser C, Löhr M, Katschinski M, Mössner I. A double-blind, randomized, multicentre, crossover study to prove equivalence of pancreatin minimicrospheres versus microspheres in exocrine pancreatic insufficiency. Aliment Pharmacol Ther. 1999 Jul;13(7): 951-7.

51 Löhr JM, Hummel FM, Pirilis KT, Steinkamp G, Körner A, Henniges F. Properties of different pancreatin preparations used in pancreatic exocrine insufficiency. Eur J Gastroenterol Hepatol. 2009 Sep;21(9):1024-31.

52 Brown A, Hughes M, Tenner S, Banks PA. Does pancreatic enzyme supplementation reduce pain in patients with chronic pancreatitis: a meta-analysis. Am J Gastroenterol. 1997 Nov;92(11):2032-5.

53 Löhr JM. Exocrine pancreatic insufficiency. Bremen: Uni-Med Verlag AG; 2007.

54 Giuliano CA, Dehoorne-Smith ML, KalePradhan PB. Pancreatic enzyme products: digesting the changes. Ann Pharmacother. 2011 May;45(5):658-66.

55 Sikkens EC, Cahen DL, van Eijck C, Kuipers EJ, Bruno MJ. Patients with exocrine insufficiency due to chronic pancreatitis are undertreated: a Dutch national survey. Pancreatology. 2012 Jan-Feb;12(1):71-3.

56 Stallings VA, Stark LJ, Robinson KA, Feranchak AP, Quinton $\mathrm{H}$; Clinical Practice Guidelines on Growth and Nutrition Subcommittee; Ad Hoc Working Group. Evidence-based practice recommendations for nutrition-related management of children and adults with cystic fibrosis and pancreatic insufficiency: results of a systematic review. J Am Diet Assoc. 2008 May;108(5):832-9.

57 Bang UC, Benfield T, Hyldstrup L, Bendtsen F, Beck Jensen JE. Mortality, cancer, and comorbidities associated with chronic pancreatitis: a Danish nationwide matched-cohort study. Gastroenterology. 2014 Apr;146(4) 989-94.

58 Mokrowiecka A, Pińkowski D, MałeckaPanas E. Assessment of quality of life in patients with chronic pancreatitis. Med Sci Monit. 2011 Oct;17(10):CR583-8.

59 Little JM. Alcohol abuse and chronic pancreatitis. Surgery. 1987 Mar;101(3):357-60.

60 Strum WB. Abstinence in alcoholic chronic pancreatitis. Effect on pain and outcome. J Clin Gastroenterol. 1995 Jan;20(1):37-41. 
61 Wilder-Smith CH, Hill L, Osler W, O'Keefe S. Effect of tramadol and morphine on pain and gastrointestinal motor function in patients with chronic pancreatitis. Dig Dis Sci. 1999 Jun;44(6):1107-16.

62 Löhr JM, Haas SL, Lindgren F, Enochsson L, Hedström A, Swahn F, et al. Conservative treatment of chronic pancreatitis. Dig Dis. 2013;31(1):43-50.

63 Cahen DL, Gouma DJ, Nio Y, Rauws EA, Boermeester MA, Busch OR, et al. Endoscopic versus surgical drainage of the pancreatic duct in chronic pancreatitis. N Engl J Med. 2007 Feb;356(7):676-84.

64 Cahen DL, Gouma DJ, Laramée P, Nio Y, Rauws EA, Boermeester MA, et al. Long-term outcomes of endoscopic vs surgical drainage of the pancreatic duct in patients with chronic pancreatitis. Gastroenterology. 2011 Nov; 141(5):1690-5.

65 Farnbacher MJ, Mühldorfer S, Wehler M, Fischer B, Hahn EG, Schneider HT. Interventional endoscopic therapy in chronic pancreatitis including temporary stenting: a definitive treatment? Scand J Gastroenterol. 2006 Jan;41(1):111-7.

66 Delhaye M, Arvanitakis M, Verset G, Cremer $M$, Devière J. Long-term clinical outcome after endoscopic pancreatic ductal drainage for patients with painful chronic pancreatitis. Clin Gastroenterol Hepatol. 2004 Dec;2(12): 1096-106.

67 Dumonceau JM, Costamagna G, Tringali A, Vahedi K, Delhaye M, Hittelet A, et al. Treatment for painful calcified chronic pancreatitis: extracorporeal shock wave lithotripsy versus endoscopic treatment: a randomised controlled trial. Gut. 2007 Apr;56(4):545-52.

68 Tantau A, Mandrutiu A, Leucuta DC, Ciobanu L, Tantau M. Prognostic factors of response to endoscopic treatment in painful chronic pancreatitis. World J Gastroenterol. 2017 Oct;23(37):6884-93.

69 Dawod E, Kahaleh M. Management of Benign and Malignant Pancreatic Duct Strictures. Clin Endosc. 2018 Mar;51(2):156-60.

70 Binmoeller KF, Jue P, Seifert H, Nam WC, Izbicki J, Soehendra N. Endoscopic pancreatic stent drainage in chronic pancreatitis and a dominant stricture: long-term results. Endoscopy. 1995 Nov;27(9):638-44.

71 Ito K, Okano N, Hara S, Takuma K, Yoshimoto K, Iwasaki S, et al. 10 Fr S-Type Plastic Pancreatic Stents in Chronic Pancreatitis Are Effective for the Treatment of Pancreatic Duct Strictures and Pancreatic Stones. Gastroenterol Res Pract. 2018 Oct;2018: 6056379.

72 Ishihara T, Yamaguchi T, Seza K, Tadenuma $\mathrm{H}$, Saisho H. Efficacy of S-type stents for the treatment of the main pancreatic duct stricture in patients with chronic pancreatitis. Scand J Gastroenterol. 2006 Jun;41(6):74450.

73 Smits ME, Badiga SM, Rauws EA, Tytgat GN, Huibregtse K. Long-term results of pancreatic stents in chronic pancreatitis. Gastrointest Endosc. 1995 Nov;42(5):461-7.

74 Vitale GC, Cothron K, Vitale EA, Rangnekar N, Zavaleta CM, Larson GM, et al. Role of pancreatic duct stenting in the treatment of chronic pancreatitis. Surg Endosc. 2004 Oct; 18(10):1431-4.
75 Eleftherladis N, Dinu F, Delhaye M, Le Moine $\mathrm{O}$, Baize M, Vandermeeren A, et al. Longterm outcome after pancreatic stenting in severe chronic pancreatitis. Endoscopy. 2005 Mar;37(3):223-30

76 Eickhoff A, Weickert U, Riemann JF. Efficacy of S-type stents for the treatment of the main pancreatic duct stricture in patients with chronic pancreatitis. Scand J Gastroenterol. 2007 Apr;42(4):537.

77 Sauer BG, Gurka MJ, Ellen K, Shami VM, Kahaleh M. Effect of pancreatic duct stent diameter on hospitalization in chronic pancreatitis: does size matter? Pancreas. 2009 Oct; 38(7):728-31.

78 Costamagna G, Bulajic M, Tringali A, Pandolfi M, Gabbrielli A, Spada C, et al. Multiple stenting of refractory pancreatic duct strictures in severe chronic pancreatitis: longterm results. Endoscopy. 2006 Mar;38(3): 254-9.

79 Tringali A, Vadalà di Prampero SF, Landi R, Bove V, Familiari P, Hamanaka J, et al. Fully covered self-expandable metal stents to dilate persistent pancreatic strictures in chronic pancreatitis: long-term follow-up from a prospective study. Gastrointest Endosc. 2018 Dec;88(6):939-46

80 Dumonceau JM, Delhaye M, Tringali A, Dominguez-Munoz JE, Poley JW, Arvanitaki $\mathrm{M}$, et al. Endoscopic treatment of chronic pancreatitis: European Society of Gastrointestinal Endoscopy (ESGE) Clinical Guideline. Endoscopy. 2012 Aug;44(8):784-800.

81 Nguyen-Tang T, Dumonceau JM. Endoscopic treatment in chronic pancreatitis, timing, duration and type of intervention. Best Pract Res Clin Gastroenterol. 2010 Jun;24(3):28198.

82 Howell DA, Dy RM, Hanson BL, Nezhad SF, Broaddus SB. Endoscopic treatment of pancreatic duct stones using a $10 \mathrm{~F}$ pancreatoscope and electrohydraulic lithotripsy. Gastrointest Endosc. 1999 Dec;50(6):829-33.

83 Beyna T, Neuhaus H, Gerges C. Endoscopic treatment of pancreatic duct stones under direct vision: revolution or resignation? Systematic review. Dig Endosc. 2018 Jan;30(1): 29-37.

84 Ito K, Igarashi Y, Okano N, Mimura T, Kishimoto Y, Hara S, et al. Efficacy of combined endoscopic lithotomy and extracorporeal shock wave lithotripsy, and additional electrohydraulic lithotripsy using the SpyGlass direct visualization system or X-ray guided EHL as needed, for pancreatic lithiasis. Biomed Res Int. 2014;2014:732781.

85 Ogura T, Okuda A, Imanishi M, Miyano A, Amano M, Nishioka N, et al. Electrohydraulic Lithotripsy for Pancreatic Duct Stones Under Digital Single-Operator Pancreatoscopy (with Video). Dig Dis Sci. 2018. [Epub ahead of print]

86 Hammel P, Couvelard A, O’Toole D, Ratouis A, Sauvanet A, Fléjou JF, et al. Regression of liver fibrosis after biliary drainage in patients with chronic pancreatitis and stenosis of the common bile duct. N Engl J Med. 2001 Feb; 344(6):418-23.

87 van Boeckel PG, Vleggaar FP, Siersema PD. Plastic or metal stents for benign extrahepatic biliary strictures: a systematic review. BMC Gastroenterol. 2009 Dec;9(1):96.
88 Costamagna G, Pandolfi M, Mutignani M, Spada C, Perri V. Long-term results of endoscopic management of postoperative bile duct strictures with increasing numbers of stents. Gastrointest Endosc. 2001 Aug;54(2):162-8.

89 Coté GA, Slivka A, Tarnasky P, Mullady DK, Elmunzer BJ, Elta G, et al. Effect of Covered Metallic Stents Compared With Plastic Stents on Benign Biliary Stricture Resolution: A Randomized Clinical Trial. JAMA. 2016 Mar;315(12):1250-7.

90 Draganov P, Hoffman B, Marsh W, Cotton $\mathrm{P}$, Cunningham J. Long-term outcome in patients with benign biliary strictures treated endoscopically with multiple stents. Gastrointest Endosc. 2002 May;55(6):680-6.

91 Cahen DL, van Berkel AM, Oskam D, Rauws EA, Weverling GJ, Huibregtse K, et al. Longterm results of endoscopic drainage of common bile duct strictures in chronic pancreatitis. Eur J Gastroenterol Hepatol. 2005 Jan; 17(1):103-8.

92 Kahl S, Zimmermann S, Genz I, Glasbrenner B, Pross M, Schulz HU, et al. Risk factors for failure of endoscopic stenting of biliary strictures in chronic pancreatitis: a prospective follow-up study. Am J Gastroenterol. 2003 Nov;98(11):2448-53.

93 Huszar G. Meta-analysis for the diagnostic accuracy of a test? Fertil Steril. 1999 Feb; 71(2):389-91

94 Pozsár J, Sahin P, László F, Forró G, Topa L. Medium-term results of endoscopic treatment of common bile duct strictures in chronic calcifying pancreatitis with increasing numbers of stents. J Clin Gastroenterol. 2004 Feb;38(2):118-23.

95 Aswad MG, Dennison AR, Neal CP, Metcalfe MS, Garcea G. Biliary stenting for benign and malignant obstructive jaundice: safe use of extended stent-change intervals. Surg Laparosc Endosc Percutan Tech. 2014 Aug;24(4):385-90.

96 Deviere J, Cremer M, Baize M, Love J, Sugai B, Vandermeeren A. Management of common bile duct stricture caused by chronic pancreatitis with metal mesh self expandable stents. Gut. 1994 Jan;35(1):122-6.

97 Dumonceau JM, Tringali A, Papanikolaou IS, Blero D, Mangiavillano B, Schmidt A, et al. Endoscopic biliary stenting: indications, choice of stents, and results: European Society of Gastrointestinal Endoscopy (ESGE) Clinical Guideline - Updated October 2017. Endoscopy. 2018 Sep;50(9):910-30.

98 Waldthaler A, Schütte K, Weigt J, Kropf S, Malfertheiner P, Kahl S. Long-term outcome of self expandable metal stents for biliary obstruction in chronic pancreatitis. JOP. 2013 Jan;14(1):57-62.

99 Khan MA, Baron TH, Kamal F, Ali B, Nollan $\mathrm{R}$, Ismail MK, et al. Efficacy of self-expandable metal stents in management of benign biliary strictures and comparison with multiple plastic stents: a meta-analysis. Endoscopy. 2017 Jul;49(7):682-94.

100 Haapamäki C, Kylänpää L, Udd M, Lindström O, Grönroos J, Saarela A, et al. Randomized multicenter study of multiple plastic stents vs. covered self-expandable metallic stent in the treatment of biliary stricture in chronic pancreatitis. Endoscopy. $2015 \mathrm{Jul}$; 47(7):605-10 
101 Siiki A, Helminen M, Sand J, Laukkarinen J. Covered self-expanding metal stents may be preferable to plastic stents in the treatment of chronic pancreatitis-related biliary strictures: a systematic review comparing 2 methods of stent therapy in benign biliary strictures. J Clin Gastroenterol. 2014 Aug; 48(7):635-43.

102 Park DH, Lee SS, Lee TH, Ryu CH, Kim HJ, Seo DW, et al. Anchoring flap versus flared end, fully covered self-expandable metal stents to prevent migration in patients with benign biliary strictures: a multicenter, prospective, comparative pilot study (with videos). Gastrointest Endosc. 2011 Jan;73(1): 64-70.

103 Mahajan A, Ho H, Sauer B, Phillips MS, Shami VM, Ellen K, et al. Temporary placement of fully covered self-expandable metal stents in benign biliary strictures: midterm evaluation (with video). Gastrointest Endosc. 2009 Aug;70(2):303-9.

104 Kasher JA, Corasanti JG, Tarnasky PR, McHenry L, Fogel E, Cunningham J. A multicenter analysis of safety and outcome of removal of a fully covered self-expandable metal stent during ERCP. Gastrointest Endosc. 2011 Jun;73(6):1292-7.

105 Jang S, Stevens T, Parsi M, Lopez R, Zuccaro G, Dumot J, et al. Association of covered metallic stents with cholecystitis and stent migration in malignant biliary stricture. Gastrointest Endosc. 2018 Apr;87(4):106170.

106 Saleem A, Leggett CL, Murad MH, Baron TH. Meta-analysis of randomized trials comparing the patency of covered and uncovered self-expandable metal stents for palliation of distal malignant bile duct obstruction. Gastrointest Endosc. 2011 Aug;74(2): 321-327.e1.

107 Li J, Li T, Sun P, Yu Q, Wang K, Chang W, et al. Covered versus Uncovered Self-Expandable Metal Stents for Managing Malignant Distal Biliary Obstruction: A MetaAnalysis. PLoS One. 2016 Feb;11(2): e0149066.

108 Sogabe Y, Kodama Y, Honjo H, Aoyama I, Muramoto Y, Koga E, et al. Tumor invasion to the arteries feeding the gallbladder as a novel risk factor for cholecystitis after metallic stent placement in distal malignant biliary obstruction. Dig Endosc. 2018 May; 30(3):380-7

109 Shimizu S, Naitoh I, Nakazawa T, Hayashi K, Miyabe K, Kondo H, et al. Predictive factors for pancreatitis and cholecystitis in endoscopic covered metal stenting for distal malignant biliary obstruction. J Gastroenterol Hepatol. 2013 Jan;28(1):68-72.

110 Zheng X, Wu J, Sun B, Wu YC, Bo ZY, Wan $\mathrm{W}$, et al. Clinical outcome of endoscopic covered metal stenting for resolution of benign biliary stricture: systematic review and meta-analysis. Dig Endosc. 2017 Mar;29(2): 198-210.

111 Devière J, Nageshwar Reddy D, Püspök A, Ponchon T, Bruno MJ, Bourke MJ, et al.; Benign Biliary Stenoses Working Group. Successful management of benign biliary strictures with fully covered self-expanding metal stents. Gastroenterology. 2014 Aug; 147(2):385-95.
112 Barthet M, Bugallo M, Moreira LS, Bastid C, Sastre B, Sahel J. Management of cysts and pseudocysts complicating chronic pancreatitis. A retrospective study of 143 patients. Gastroenterol Clin Biol. 1993;17(4):270-6.

113 Gouyon B, Lévy P, Ruszniewski P, Zins M, Hammel P, Vilgrain V, et al. Predictive factors in the outcome of pseudocysts complicating alcoholic chronic pancreatitis. Gut. 1997 Dec;41(6):821-5.

114 Rosso E, Alexakis N, Ghaneh P, Lombard M, Smart HL, Evans J, et al. Pancreatic pseudocyst in chronic pancreatitis: endoscopic and surgical treatment. Dig Surg. 2003;20(5): 397-406.

115 Varadarajulu S, Bang JY, Sutton BS, Trevino JM, Christein JD, Wilcox CM. Equal efficacy of endoscopic and surgical cystogastrostomy for pancreatic pseudocyst drainage in a randomized trial. Gastroenterology. 2013 Sep;145(3):583-90.e1.

116 Bradley EL 3rd, Clements JL Jr, Gonzalez AC. The natural history of pancreatic pseudocysts: a unified concept of management. Am J Surg. 1979 Jan;137(1):135-41.

117 Nealon WH, Walser E. Duct drainage alone is sufficient in the operative management of pancreatic pseudocyst in patients with chronic pancreatitis. Ann Surg. 2003 May; 237(5):614-20.

118 Kolodziejczyk E, Jurkiewicz E, Pertkiewicz J, Wejnarska K, Dadalski M, Kierkus J, et al. MRCP Versus ERCP in the Evaluation of Chronic Pancreatitis in Children: Which Is the Better Choice? Pancreas. 2016 Sep;45(8): 1115-9.

119 Dumonceau JM. Endoscopic therapy for chronic pancreatitis. Gastrointest Endosc Clin N Am. 2013 Oct;23(4):821-32.

120 Denzer U, Beilenhoff U, Eickhoff A, Faiss S, Hüttl P, In der Smitten S, et al.; Deutsche Gesellschaft für Gastroenterologie, Verdauungsund Stoffwechselkrankheiten. [S2k guideline: quality requirements for gastrointestinal endoscopy, AWMF registry No. 021-022]. Z Gastroenterol. 2015 Dec;53(12):E1-227.

121 Stier MW, Waxman I. Lumen-Apposing Metal Stents: Which One and Why? Gastrointest Endosc Clin N Am. 2018 Apr;28(2): 207-17.

122 Bang JY, Navaneethan U, Hasan MK, Sutton B, Hawes R, Varadarajulu S. Non-superiority of lumen-apposing metal stents over plastic stents for drainage of walled-off necrosis in a randomised trial. Gut. 2018. [Epub ahead of print]

123 Bang JY, Hawes R, Bartolucci A, Varadarajulu S. Efficacy of metal and plastic stents for transmural drainage of pancreatic fluid collections: a systematic review. Dig Endosc. 2015 May;27(4):486-98.

124 Yang J, Chen YI, Friedland S, Holmes I, Paiji C, Law R, et al. Lumen-apposing stents versus plastic stents in the management of pancreatic pseudocysts: a large, comparative, international, multicenter study. Endoscopy. 2018. [Epub ahead of print]

125 Noble M, Gress FG. Techniques and results of neurolysis for chronic pancreatitis and pancreatic cancer pain. Curr Gastroenterol Rep. 2006 Apr;8(2):99-103.

126 Santosh D, Lakhtakia S, Gupta R, Reddy DN, Rao GV, Tandan M, et al. Clinical trial: a randomized trial comparing fluoroscopy guided percutaneous technique vs. endoscopic ultrasound guided technique of coeliac plexus block for treatment of pain in chronic pancreatitis. Aliment Pharmacol Ther. 2009 May;29(9):979-84.

127 Michaels AJ, Draganov PV. Endoscopic ultrasonography guided celiac plexus neurolysis and celiac plexus block in the management of pain due to pancreatic cancer and chronic pancreatitis. World J Gastroenterol. 2007 Jul;13(26):3575-80.

128 Enochsson L, Swahn F, Arnelo U, Nilsson M, Löhr M, Persson G. Nationwide, population-based data from 11,074 ERCP procedures from the Swedish Registry for Gallstone Surgery and ERCP. Gastrointest Endosc. 2010 Dec;72(6):1175-84, 1184. e1-3.

129 Fujii-Lau LL, Levy MJ. Endoscopic ultrasound-guided pancreatic duct drainage. J Hepatobiliary Pancreat Sci. 2015 Jan;22(1): 51-7.

130 Kamata K, Takenaka M, Minaga K, Sakurai T, Watanabe T, Nishida N, et al. EUS-Guided Pancreatic Duct Drainage for Repeat Pancreatitis in a Patient with Pancreatic Cancer. Oncology. 2017;93 Suppl 1:87-8.

131 Sun C, Jin ZD, Pan X, Wang D, Li ZS. Endoscopic ultrasound-guided transgastric pancreatic duct drainage after Whipple surgery in a patient with chronic pancreatitis. Endoscopy. 2011;43 Suppl 2 UCTN:E182-3.

132 Wang K, Zhu J, Xing L, Wang Y, Jin Z, Li Z Assessment of efficacy and safety of EUSguided biliary drainage: a systematic review. Gastrointest Endosc. 2016 Jun;83(6):121827.

133 Dhir V, Bhandari S, Bapat M, Maydeo A. Comparison of EUS-guided rendezvous and precut papillotomy techniques for biliary access (with videos). Gastrointest Endosc. 2012 Feb;75(2):354-9.

134 Oh D, Park DH, Song TJ, Lee SS, Seo DW, Lee SK, et al. Optimal biliary access point and learning curve for endoscopic ultrasound-guided hepaticogastrostomy with transmural stenting. Therap Adv Gastroenterol. 2017 Jan; 10(1):42-53.

135 Poincloux L, Rouquette O, Buc E, Privat J, Pezet D, Dapoigny M, et al. Endoscopic ultrasound-guided biliary drainage after failed ERCP: cumulative experience of 101 procedures at a single center. Endoscopy. 2015 Sep;47(9):794-801.

136 Paik WH, Lee TH, Park DH, Choi JH, Kim SO, Jang S, et al. EUS-Guided Biliary Drainage Versus ERCP for the Primary Palliation of Malignant Biliary Obstruction: A Multicenter Randomized Clinical Trial. Am J Gastroenterol. 2018 Jul;113(7):987-97.

137 Park JK, Woo YS, Noh DH, Yang JI, Bae SY, Yun HS, et al. Efficacy of EUS-guided and ERCP-guided biliary drainage for malignant biliary obstruction: prospective randomized controlled study. Gastrointest Endosc. 2018 Aug;88(2):277-82.

138 Bang JY, Navaneethan U, Hasan M, Hawes R, Varadarajulu S. Stent placement by EUS or ERCP for primary biliary decompression in pancreatic cancer: a randomized trial (with videos). Gastrointest Endosc. 2018 Jul; 88(1):9-17. 